\title{
Tumor-associated macrophage infiltration is highly associated with PD-L1 expression in gastric adenocarcinoma
}

\author{
Kazuto Harada $^{1}$ - Xiaochuan Dong ${ }^{1} \cdot$ Jeannelyn S. Estrella $^{2} \cdot$ Arlene M. Correa $^{3} \cdot$ Yan Xu $^{1,8} \cdot$ Wayne L. Hofstetter $^{3}$. \\ Kazuki Sudo $^{1} \cdot$ Hisashi Onodera $^{4} \cdot$ Koyu Suzuki $^{5} \cdot$ Akihiro Suzuki $^{6} \cdot$ Randy L. Johnson ${ }^{7} \cdot$ Zhenning Wang $^{8}$. \\ Shumei Song ${ }^{1} \cdot$ Jaffer A. Ajani $^{1}$
}

Received: 11 May 2017 / Accepted: 4 August 2017 / Published online: 11 August 2017

(C) The International Gastric Cancer Association and The Japanese Gastric Cancer Association 2017

\begin{abstract}
Background Programmed death ligand 1 (PD-L1) is a key protein upregulated by tumor cells to suppress immune responses. Tumor-associated macrophages (TAMs) play a major role in this immunosuppression, but the relationship between PD-L1 expression and TAMs remains unclear in gastric adenocarcinoma (GAC). We simultaneously examined expression of PD-L1 and TAMs in GAC.

Methods We performed immunohistochemical staining for PD-L1, CD68 (pan-macrophage), and CD163 (M2-like macrophage) in 217 GAC samples using a tissue microarray. Expression of PD-L1 and CD68- and CD163-positive cells was evaluated using the Cytoplasmic V2.0 algorithm in
\end{abstract}

Jaffer A. Ajani

jajani@mdanderson.org

1 Department of Gastrointestinal Medical Oncology, Unit 0426, The University of Texas MD Anderson Cancer Center, 1515 Holcombe Blvd, Houston, TX 77030, USA

2 Department of Pathology, The University of Texas MD Anderson Cancer Center, Houston, TX 77030, USA

3 Department of Thoracic and Cardiovascular Surgery, The University of Texas MD Anderson Cancer Center, Houston, TX 77030, USA

4 Education Center, St. Lukes University, Tokyo 104-8560, Japan

5 Department of Pathology, St. Lukes University, Tokyo 104-8560, Japan

6 Department of Gastrointestinal Surgery, St. Lukes University, Tokyo 104-8560, Japan

7 Department of Cancer Biology, The University of Texas MD Anderson Cancer Center, Houston, TX 77030, USA

8 Department of Surgical Oncology and General Surgery, First Hospital of China Medical University, Shenyang 110001, People's Republic of China
Aperio ImageScope software, and logistic regression analysis was used to compare expression patterns between groups. Results Thirty-one samples (14\%) were positive for PD-L1 expression. The mean ( \pm standard error) rates of infiltration were $6.83 \pm 0.38 \%$ for CD68-positive cells and $6.16 \pm 0.29 \%$ for CD163-positive cells. The mean rate of CD163-positive cell infiltration was significantly higher in diffuse GAC than in intestinal GAC (diffuse $n=111,6.91 \%$; intestinal $n=91$, $5.26 \% ; p=0.006)$, but the mean rate of CD68-positive cell infiltration was similar between these types $(p=0.38)$. The mean infiltration rates of CD68- and CD163-positive cells in PD-L1-positive GAC were significantly higher than in PDL1-negative GAC (CD68 $p=0.0002$; CD163 $p<0.0001)$. In multivariate logistic regression analyses, CD163-positive cell infiltration was associated with PD-L1 expression (odds ratio 1.13 ; 95\% confidence interval $1.02-1.25 ; p=0.021$ ).

Conclusion M2-like macrophage infiltration is highly associated with PD-L1 expression in GAC cells, suggesting that macrophage infiltration can serve as a potential therapeutic target.

Keywords Gastric adenocarcinoma Programmed death protein $1 \cdot$ Tumor microenvironment $\cdot$ Macrophages

\section{Introduction}

Gastric adenocarcinoma (GAC) is the fifth most common cancer ( 951,000 cases per year) and the third leading cause of cancer-related mortality worldwide $(723,000$ deaths per year) [1]. Despite the development of multimodality therapies such as surgery, systemic therapy, and radiation therapy, the mortality rates for GAC remain high [2]. Immune checkpoint blockade has recently received much attention for prolonging patient survival in GAC. 
Programmed death protein 1 (PD-1) in T cells and its ligands (PD-L1/PD-L2) in tumor cells inhibit the response of $\mathrm{T}$ cells to tumor cells. Therefore, $\mathrm{PD}-1 / \mathrm{L} 1$ inhibitors have been developed for clinical application and shown to be efficacious in several cancers [3-5]. Many ongoing clinical trials are evaluating the benefit of PD-1/L1 inhibitors in GAC, and early results are promising [6-10]. Importantly, GAC is more sensitive to PD-1/L1 inhibitors when PD-L1 expression is present, and some trials have enrolled only patients with PD-L1 expression [8-10]. Thus, discovering the mechanisms and the predictive markers of PD-L1 expression can further refine selection of patients with GAC most likely to benefit from PD-1/L1 inhibitors.

The tumor microenvironment, especially immune cell infiltration, appears to be associated with PD-L1 expression. For instance, in the beginning, infiltrating $\mathrm{T}$ cell and $\mathrm{B}$ cells may be targeting tumor cells and subsequently facilitate PD-1 pathway [11]. Moreover, tumor-associated macrophages (TAMs), especially M2 macrophages, are also promoting an immunosuppressive microenvironment [12, 13]. Several reports have shown that TAMs overexpress PD-L1 themselves and suppress cytotoxic T lymphocyte function against tumor cells [14]. However, the relationship between PD-L1 expression in tumor cells and TAMs remains unclear.

In the current study, we performed immunohistochemical staining of PD-L1, CD68 (pan-macrophage), and CD163 (M2-like macrophage) in 217 GAC samples using a tissue microarray (TMA) and evaluated the relationship between PD-L1 expression in GAC cells and macrophage infiltration as well as the clinicopathologic features.

\section{Materials and methods}

\section{Study subjects}

This study retrospectively evaluated 217 GAC samples (using TMA) from patients who underwent resection at The University of Texas MD Anderson Cancer Center (Houston, USA) or at St. Luke's International Hospital (Tokyo, Japan) between March 1999 and September 2011. The analysis excluded patients who underwent palliative resection and those whose tissue samples were unavailable for TMA. Tumors were staged according to the American Joint Committee on Cancer Staging Manual (6th edition) [15]. Overall survival was defined as the time between the treatment start date and the date of death. All procedures were followed in accordance with the ethical standards of institutional and national committees on human experimentation and with the Helsinki Declaration of 1964 and later versions. Informed consent or a substitute for it was obtained from all patients included in the study.

\section{TMA construction}

Representative areas of the tumors were marked by a gastrointestinal pathologist (J.S.E.) on hematoxylin-eosin-stained sections of formalin-fixed, paraffin-embedded archival GAC or normal (control) gastrointestinal tissue. Using an automated tissue arrayer (Beecher ATA-27; Estigen OU, Tartu, Estonia), we extracted duplicate 1-mm-diameter cores from the designated areas of the corresponding paraffin blocks and placed the cores in the TMA blocks according to prearranged maps. Staggering of cores was used to ensure proper orientation and identification of each case. Sections that were $5 \mu \mathrm{m}$ thick were cut from the TMA blocks for immunohistochemical analysis.

\section{Immunohistochemistry}

TMA slides were dewaxed in xylene and ethanol and steamed in a 2100 Retriever (Aptum Bioologics, Southampton, UK) with pH 6.0 sodium citrate buffer to retrieve antigen epitopes. Once the samples had cooled, endogenous peroxidase activity was blocked using 3\% hydrogen peroxide, and biotin was blocked using a biotin blocking kit. The slides were incubated at $4{ }^{\circ} \mathrm{C}$ overnight with a primary antibody: PD-L1 with an anti-human PD-L1 rabbit monoclonal antibody (dilution 1:100; clone SP142; Spring Bioscience, Pleasanton, CA, USA), CD68 with an anti-human CD68 mouse monoclonal antibody (dilution 1:200; KP-1; Agilent, Santa Clara, CA, USA), or CD163 with an antihuman CD163 mouse monoclonal antibody (dilution 1:200; NCL-L-CD163; Leica, Nussloch, Germany). The secondary antibody was a ready-to-use VECTASTAIN ABC HRP Kit (Vector Laboratories, Burlingame, CA, USA).

\section{Evaluation of immunohistochemistry}

The density of CD68- and CD163-positive cells was evaluated using computer-assisted image analysis and the Cytoplasmic V2.0 algorithm in Aperio ImageScope software (Leica, Nussloch, Germany). Density was calculated as the area with positive staining divided by the total area analyzed. Fifteen patient samples could not be evaluated for the CD163-positive cell area owing to sample conditions.

PD-L1 expression on tumor cells, not stroma, was immunohistochemically analyzed by an experienced pathologist (X. Dong) without knowledge of the clinical data or CD68or CD163-positive cell density. Samples were considered PD-L1 positive if $>1 \%$ of tumor cells expressed PD-L1. One patient sample could not be evaluated for PD-L1 expression owing to the sample condition. Cancer and stromal cells were distinguished by cell morphology, structures, and nucleus status. 


\section{Statistical methods}

IBM SPSS Statistics Software, version 23, was used for all statistical analyses. All $\mathrm{p}$ values were two-sided, and the statistical significance cutoff was $p \leq 0.05$. Means were compared using the independent-sample KruskalWallis test. Association between categorical variables was assessed using the Pearson chi-square test or Fisher's exact test, accordingly. We performed univariate and multivariate logistic regression analyses to assess the predictors of associated with positive PD-L1 and estimated the odds ratios with $95 \%$ confidence intervals. Factors with $p \leq 0.25$ in the univariate analyses were entered into the multivariate analyses. To assess the interaction between the variables, we cross-correlated the intratumoral density of CD163-positive cells with another variable of interest in the odds ratio for PD-L1 expression in GAC cells, and the interaction was evaluated. The hazard ratio (HR) of mortality was assessed by the Cox regression model.

\section{Results}

\section{PD-L1 expression and CD68+ and CD163+ macrophage infiltration in GAC}

We performed immunohistochemical staining for PD-L1, CD68, and CD163 in 217 GAC tissue samples using a TMA (Fig. 1). Thirty-one of the 216 evaluable GAC samples $(14 \%)$ stained positive for PD-L1 expression in cancer cells and 24 samples (11\%) stained positive in stroma
(Table 1). None of the clinicopathologic variables was associated with PD-L1 expression (all $p>0.05$ ).

The intratumoral density of CD68-positive cells in the 217 GAC samples was distributed as follows: mean 6.83; median 5.24; standard deviation 5.65; range 0.48-32.4; interquartile range $2.88-8.73$ (Table 2). The intratumoral density of CD163-positive cells in the 202 evaluable GAC samples was distributed as follows: mean 6.16 ; median 5.06; standard deviation 4.24; range 0.37-22.7; interquartile range 3.28-7.94 (Table 2). The intratumoral density of CD163-positive cells in diffuse GAC was significantly higher than in intestinal GAC ( $p<0.006$; Table 2$)$. However, the intratumoral density of CD68-positive cells was not associated with the Lauren classification.

\section{Relationship between PD-L1 expression and CD68- or CD163-positive cell intratumoral density in GAC}

We then examined the relationship between PD-L1 expression and the intratumoral density of CD68- and CD163-positive cells (Fig. 2). The density of CD68- and CD163-positive cells in PD-L1-positive GAC samples was significantly higher than in PD-L1-negative GAC samples $($ CD68 $p=0.0002$; CD163 $p<0.0001)$. These results indicate that $\mathrm{CD} 163$ density was more strongly associated with PD-L1 expression in GAC cells than CD68 density was.

PD-L1 expression in stroma was also significantly associated with higher CD68- or CD163-positive cell intratumoral density (CD68 $p \leq 0.0001$; CD163 $p=0.0227$ ).
Fig. 1 Immunohistochemistry staining for PD-L1, CD68, and CD163 expression in gastric adenocarcinoma tissues. The left panel shows negative staining for PD-L1 and low macrophage density. The right panel shows positive staining for PD-L1 and high macrophage density

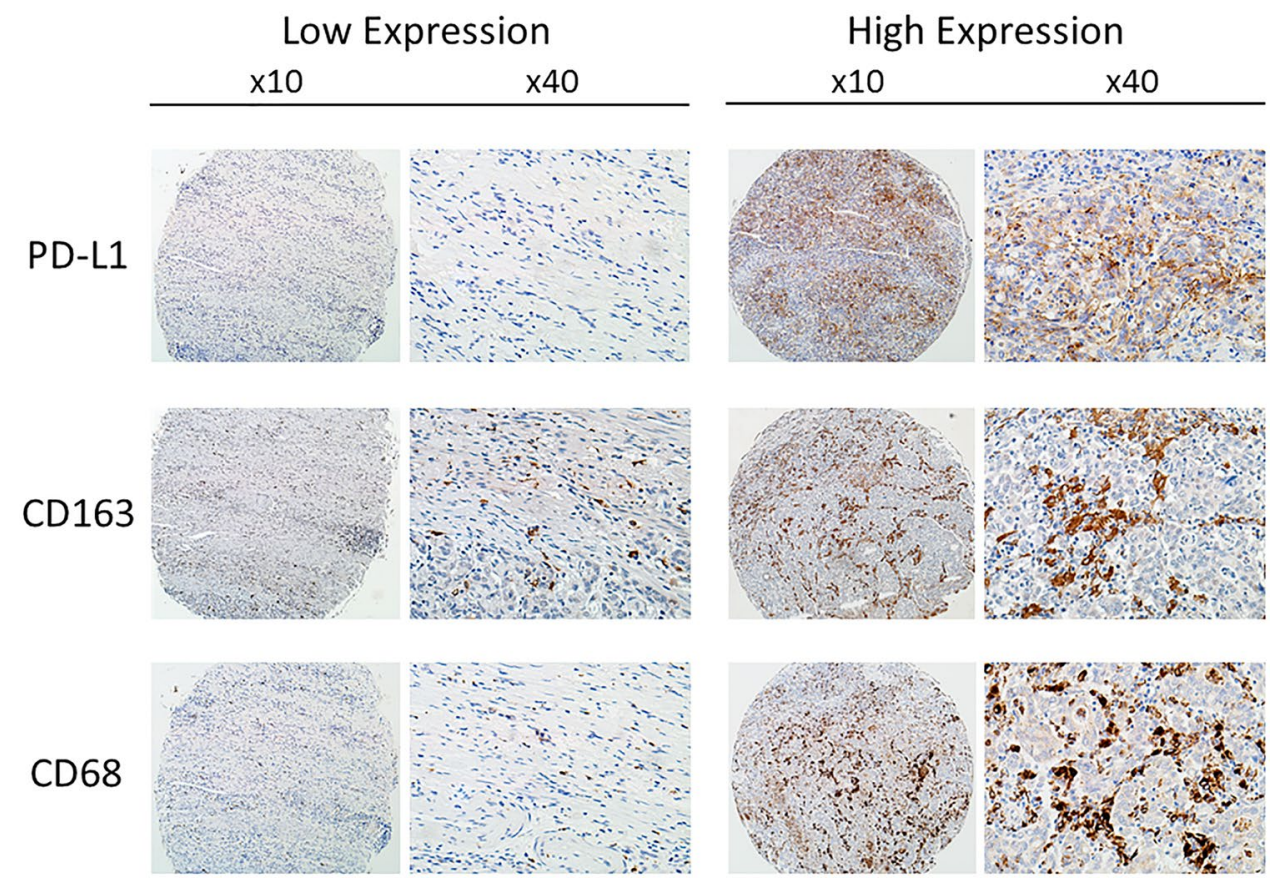


Table 1 PD-L1 expression (via immunohistochemistry) and clinical features in 216 evaluable gastric adenocarcinoma patient samples

\begin{tabular}{|c|c|c|c|c|c|c|c|}
\hline \multirow[t]{2}{*}{ Clinical or pathologic feature } & \multirow[t]{2}{*}{ Total no. } & \multicolumn{3}{|c|}{$\begin{array}{l}\text { PD-L1 expression in cancer } \\
\text { cell }\end{array}$} & \multicolumn{3}{|c|}{ PD-L1 expression in stroma } \\
\hline & & Positive & Negative & $p$ value & Positive & Negative & $p$ value \\
\hline All cases & 216 & $31(14)$ & $185(86)$ & - & $24(11)$ & $192(89)$ & - \\
\hline Age & & & & 0.11 & & & 0.59 \\
\hline$<70$ years & 119 & $13(11)$ & $106(89)$ & & $12(10)$ & $107(90)$ & \\
\hline$\geq 70$ years & 97 & $18(19)$ & $79(81)$ & & $12(12)$ & $85(88)$ & \\
\hline Sex & & & & 0.27 & & & 0.34 \\
\hline Male & 134 & $22(16)$ & $112(84)$ & & $17(13)$ & $117(87)$ & \\
\hline Female & 82 & $9(11)$ & $73(89)$ & & $7(9)$ & $75(91)$ & \\
\hline Race/ethnicity & & & & 0.091 & & & 0.28 \\
\hline White & 33 & $2(6)$ & $31(94)$ & & $2(6)$ & $31(94)$ & \\
\hline Japanese & 151 & 27 (18) & $124(82)$ & & $20(13)$ & $131(87)$ & \\
\hline Hispanic & 32 & $2(6)$ & $30(94)$ & & $2(6)$ & $30(94)$ & \\
\hline Lauren classification & & & & 0.60 & & & 0.09 \\
\hline Intestinal & 100 & $13(13)$ & $87(87)$ & & $15(15)$ & $85(85)$ & \\
\hline Diffuse & 116 & $18(16)$ & $98(84)$ & & $9(8)$ & $107(92)$ & \\
\hline Preoperative therapy & & & & 0.097 & & & 0.80 \\
\hline None & 165 & $27(16)$ & $138(84)$ & & $17(10)$ & $148(90)$ & \\
\hline Chemotherapy & 29 & $4(14)$ & $25(86)$ & & $4(14)$ & $25(86)$ & \\
\hline Chemoradiotherapy & 22 & $0(0)$ & $22(100)$ & & $3(14)$ & $19(86)$ & \\
\hline Tumor depth & & & & 0.99 & & & 0.34 \\
\hline $\mathrm{T} 1$ & 31 & $4(13)$ & $27(87)$ & & $6(19)$ & $25(81)$ & \\
\hline $\mathrm{T} 2$ & 104 & $16(15)$ & $88(85)$ & & $13(13)$ & $91(87)$ & \\
\hline $\mathrm{T} 3$ & 66 & $9(14)$ & $57(86)$ & & $4(6)$ & $62(94)$ & \\
\hline $\mathrm{T} 4$ & 14 & $2(14)$ & $12(86)$ & & $1(7)$ & $13(93)$ & \\
\hline TX & 1 & $1(100)$ & $0(0)$ & & $0(0)$ & $1(100)$ & \\
\hline $\mathrm{LN}$ involvement & & & & 0.25 & & & 0.83 \\
\hline No & 67 & $11(16)$ & $56(84)$ & & $8(12)$ & $59(88)$ & \\
\hline N1 & 84 & $7(8)$ & $77(92)$ & & $10(12)$ & $74(88)$ & \\
\hline $\mathrm{N} 2$ & 27 & $5(19)$ & $22(81)$ & & $3(11)$ & $24(89)$ & \\
\hline N3 & 33 & $6(18)$ & $27(82)$ & & $2(6)$ & $31(94)$ & \\
\hline NX & 5 & $2(40)$ & $3(60)$ & & $1(20)$ & $4(80)$ & \\
\hline Stage & & & & 0.64 & & & 0.35 \\
\hline I & 67 & $11(16)$ & $56(84)$ & & $11(16)$ & $56(84)$ & \\
\hline II & 49 & $4(8)$ & $45(92)$ & & $3(6)$ & $46(94)$ & \\
\hline III & 38 & $6(16)$ & $32(84)$ & & $5(13)$ & $33(87)$ & \\
\hline IV & 59 & $10(17)$ & $49(83)$ & & $5(8)$ & $54(92)$ & \\
\hline$X$ & 3 & $0(0)$ & $3(100)$ & & $0(0)$ & $3(100)$ & \\
\hline
\end{tabular}

$L N$ lymph node

\section{Predictive factors for PD-L1 expression in GAC}

To identify factors predicting positive PD-L1 expression in GAC cells, we performed univariate and multivariate logistic regression analyses. In the univariate analysis, PD-L1 expression in GAC cells was associated with the density of CD68- and CD163-positive cells (Table 3). In the multivariate analysis, which included features with $p<0.2$ in the univariate analysis (age, preoperative therapy, and density of CD68- and CD163-positive cells), only the density of
CD163-positive cells was associated with PD-L1 expression in GAC cells (odds ratio 1.13; 95\% confidence interval $1.02-1.25 ; p=0.021$; Table 3 ).

\section{PD-L1 expression and density of CD163-positive cells in various strata}

Additionally, we examined whether the influence of CD163-positive cell density on PD-L1 expression in GAC cells was associated with any of the clinical or 
Table 2 Density of CD68- and CD163-positive cells in the tumor field and clinical features in 217 samples of gastric adenocarcinoma

\begin{tabular}{|c|c|c|c|c|c|c|}
\hline \multirow[t]{2}{*}{ Clinical or pathologic feature } & \multicolumn{3}{|l|}{ CD68 } & \multicolumn{3}{|l|}{ CD 163} \\
\hline & Total no. & CD68 (\%) (Mean $\pm \mathrm{SE})$ & $p$ value & Total no. & $\begin{array}{l}\text { CD } 163(\%) \\
(\text { Mean } \pm \text { SE) }\end{array}$ & $p$ value \\
\hline All cases & 217 & $6.83 \pm 0.38$ & - & $202^{\mathrm{a}}$ & $6.16 \pm 0.30$ & - \\
\hline Age & & & 0.41 & & & 0.17 \\
\hline$<70$ years & 120 & $6.43 \pm 0.47$ & & 111 & $5.71 \pm 0.37$ & \\
\hline$\geq 70$ years & 97 & $7.32 \pm 0.63$ & & 91 & $6.72 \pm 0.48$ & \\
\hline Sex & & & 0.82 & & & 0.41 \\
\hline Male & 135 & $6.81 \pm 0.46$ & & 128 & $6.14 \pm 0.40$ & \\
\hline Female & 82 & $6.85 \pm 0.68$ & & 74 & $6.21 \pm 0.44$ & \\
\hline Race/ethnicity & & & 0.06 & & & 0.44 \\
\hline White & 33 & $4.43 \pm 0.68$ & & 28 & $4.87 \pm 0.64$ & \\
\hline Japanese & 152 & $7.35 \pm 0.46$ & & 145 & $6.47 \pm 0.37$ & \\
\hline Hispanic & 32 & $6.82 \pm 1.13$ & & 29 & $5.90 \pm 0.74$ & \\
\hline Lauren classification & & & 0.43 & & & 0.006 \\
\hline Intestinal & 100 & $6.47 \pm 0.56$ & & 91 & $5.26 \pm 0.37$ & \\
\hline Diffuse & 117 & $7.14 \pm 0.53$ & & 111 & $6.91 \pm 0.44$ & \\
\hline Preoperative therapy & & & 0.56 & & & 0.58 \\
\hline None & 166 & $6.99 \pm 0.44$ & & 158 & $6.31 \pm 0.34$ & \\
\hline Chemotherapy & 29 & $6.75 \pm 1.19$ & & 26 & $5.86 \pm 0.82$ & \\
\hline Chemoradiotherapy & 22 & $5.79 \pm 0.98$ & & 18 & $5.29 \pm 0.95$ & \\
\hline Tumor depth & & & 0.98 & & & 0.29 \\
\hline $\mathrm{T} 1$ & 32 & $6.66 \pm 082$ & & 27 & $5.82 \pm 0.70$ & \\
\hline $\mathrm{T} 2$ & 104 & $6.89 \pm 0.54$ & & 100 & $5.86 \pm 0.44$ & \\
\hline $\mathrm{T} 3$ & 66 & $6.61 \pm 0.71$ & & 64 & $6.74 \pm 0.49$ & \\
\hline $\mathrm{T} 4$ & 14 & $8.26 \pm 2.18$ & & 10 & $7.07 \pm 1.92$ & \\
\hline TX & 1 & 0.81 & & 1 & 0.67 & \\
\hline Lymph node involvement & & & 0.37 & & & 0.14 \\
\hline No & 68 & $7.10 \pm 0.65$ & & 63 & $6.41 \pm 0.60$ & \\
\hline N1 & 84 & $6.46 \pm 0.65$ & & 78 & $5.42 \pm 0.41$ & \\
\hline $\mathrm{N} 2$ & 27 & $5.98 \pm 0.80$ & & 25 & $6.27 \pm 0.73$ & \\
\hline N3 & 33 & $8.13 \pm 1.14$ & & 31 & $7.56 \pm 0.86$ & \\
\hline NX & 5 & $5.40 \pm 2.53$ & & 5 & $5.43 \pm 1.88$ & \\
\hline Stage & & & 0.51 & & & 0.28 \\
\hline I & 68 & $7.19 \pm 0.68$ & & 62 & $6.13 \pm 0.58$ & \\
\hline II & 49 & $5.92 \pm 0.69$ & & 47 & $5.24 \pm 0.54$ & \\
\hline III & 38 & $7.12 \pm 1.09$ & & 37 & $6.32 \pm 0.60$ & \\
\hline IV & 59 & $7.17 \pm 0.74$ & & 53 & $6.98 \pm 0.63$ & \\
\hline$X$ & 3 & $3.27 \pm 1.23$ & & 3 & $5.18 \pm 2.90$ & \\
\hline
\end{tabular}

SE standard error

${ }^{\text {a }}$ Fifteen samples could not be evaluated for CD163 owing to sample conditions

pathologic variables, including age, sex, Lauren classification, preoperative therapy, tumor depth, lymph node involvement, and tumor stage. The relationship between CD163-positive cell density and PD-L1 expression in GAC cells was not modified by any clinical or pathologic variables (all $p$ for interactions $>0.05$; Fig. 3 ).

\section{Prognosis}

Among the 217 evaluated patients, 89 patients had died at the last follow-up period. The median follow-up time for censored patients was 5.54 years. We performed a Cox regression analysis of overall survival. All immunohistochemical statuses, such as PD-L1 expression in GAC and 
Fig. 2 Associations between PD-L1 expression and the infiltration area of CD68 and CD163 positive cells. a PD-L1 expression in GAC cells and CD68. b PD-L1 expression in GAC cells and CD163. c PD-L1 expression in stroma and CD68. d PD-L1 expression in stroma and CD163
(A) PD-L1 in cancer cells and CD68

(B) PD-L1 in cancer cells and CD163

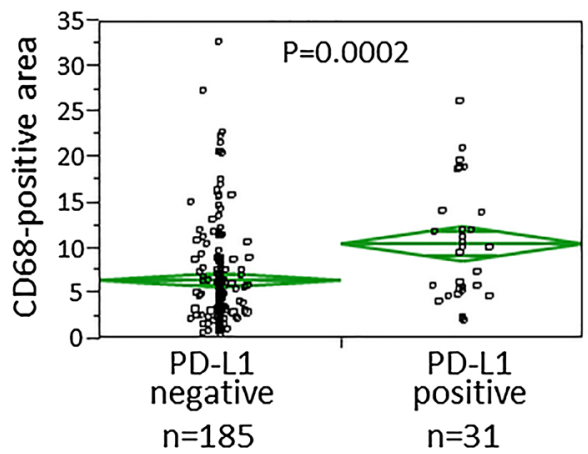

(C) PD-L1 in stroma and CD68

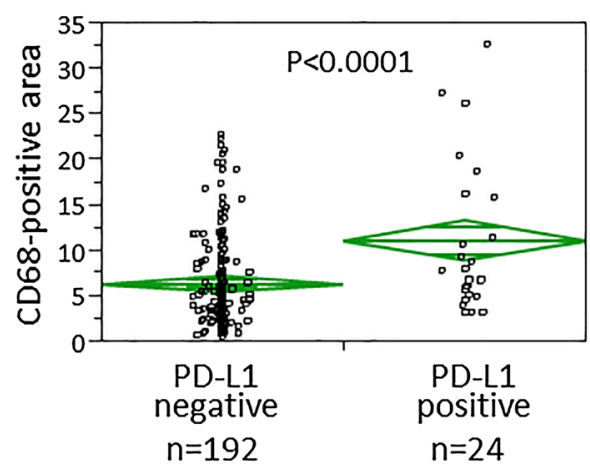

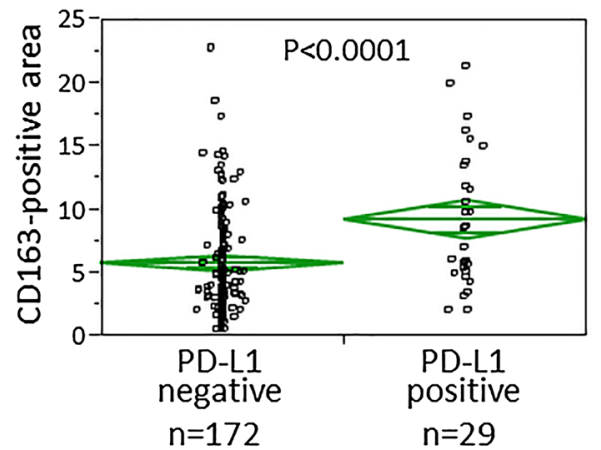

(D) PD-L1 in stroma and CD163

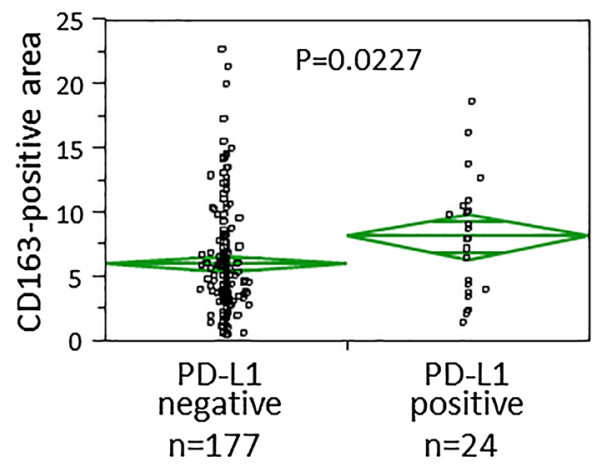

intratumoral density of CD68- and CD163-positive cells (continuous variable), was not associated with overall mortality (all univariate analysis $p \geq 0.05$; Table 4 ).

\section{Discussion}

We evaluated immunohistochemical staining of PD-L1, CD68, and CD163 in 217 GAC samples from a TMA and found that PD-L1 expression in GAC is independently associated with CD163-positive cell infiltration, suggesting that M2-like macrophages potentially facilitate PD-L1 expression in GAC tumor cells. These results also suggest that M2 macrophage infiltration could be used as a predictive marker for PD-L1 expression and M2 macrophages could serve as a potential therapeutic target.

Several prior reports have established that PD-L1 expression can range from 25 to $65 \%$ in gastric cancers; in our TMA, it was only $14 \%$ [16-20]. This rate may vary among studies for many reasons, including heterogeneity and phenotypic differences in the samples, patient differences in cancer stage or prior therapy, and the use of different PD-L1 antibodies. To date, four PD-L1 antibodies (22C3, 28-8, SP142, and SP263) have been studied and are in widespread use. A phase 1 study of atezolizumab showed that the PD-L1-positive rate was 5/141 (3.5\%) in GAC cells and 18/141 (12.8\%) in stromal cells, using the SP142 antibody and PD-L1 positivity defined as $>5 \%$ of cells [21]. The KEYNOTE-012 study showed that the PD-L1-positive rate in both GAC cells and stromal cells was $40 \%$, using the $22 \mathrm{C} 3$ antibody and PD-L1 positivity defined as $>1 \%$ of cells. In a study of 35 patients whose tissue samples were positive for PD-L1 expression, 6 (17\%) had PD-L1-positive tumor cells, which is similar to our findings [6]. Given these variations in the literature, we consider the PD-L1-positive rate in our study is valid.

The relationship between TAMs and PD-L1 expression in tumor cells is not well understood. There is some evidence that TAMs, especially M2 macrophages, express PD-L1 on their surface and directly suppress T cell responses. This is suggested by clinical trial results showing that PD-L1 expression in tumor stroma is a predictive marker for patient outcomes after immune checkpoint blockade therapy $[6,12]$. TAMs have been found to release several factors, such as cytokines, chemokines, polypeptide growth factors, hormones, matrix remodeling proteases, and metabolites. TAMS have also been shown to directly or indirectly promote many important features of tumor progression, such as angiogenesis, invasion, proliferation, and the tumor microenvironment [22]. 
Table 3 Univariate and multivariate analysis of factors associated with PD-L1 expression in cancer cells

\begin{tabular}{|c|c|c|c|c|}
\hline \multirow[t]{2}{*}{ Clinical or pathologic feature } & \multicolumn{2}{|l|}{ Univariate } & \multicolumn{2}{|l|}{ Multivariate } \\
\hline & Odds ratio $(95 \% \mathrm{CI})$ & $p$ value & Odds ratio $(95 \% \mathrm{CI})$ & $p$ value \\
\hline \multicolumn{5}{|l|}{ Age } \\
\hline$<70$ years & 1 (reference) & & 1 (reference) & \\
\hline$\geq 70$ years & $1.86(0.86-4.02)$ & 0.12 & $1.58(0.66-3.86)$ & 0.30 \\
\hline \multicolumn{5}{|l|}{ Sex } \\
\hline Male & 1 (reference) & & & \\
\hline Female & $0.63(0.26-1.40)$ & 0.26 & & \\
\hline \multicolumn{5}{|l|}{ Race/ethnicity } \\
\hline White & 1 (reference) & 0.46 & & \\
\hline Japanese & $3.37(0.94-21.6)$ & & & \\
\hline Hispanic & $1.03(0.12-9.06)$ & & & \\
\hline \multicolumn{5}{|l|}{ Lauren classification } \\
\hline Intestinal & 1 (reference) & & & \\
\hline Diffuse & $1.22(0.57-2.70)$ & 0.60 & & \\
\hline \multicolumn{5}{|l|}{ Preoperative therapy } \\
\hline None & 1 (reference) & & 1 (reference) & \\
\hline Present & $0.43(0.12-1.18)$ & 0.11 & $1.03(0.19-4.77)$ & 0.97 \\
\hline \multicolumn{5}{|l|}{ Tumor depth } \\
\hline $\mathrm{T} 1-2$ & 1 (reference) & & & \\
\hline T3-4 & $0.91(0.50-2.49)$ & 0.45 & & \\
\hline \multicolumn{5}{|l|}{ Lymph node involvement } \\
\hline None & 1 (reference) & & & \\
\hline Present & $0.72(0.59-3.07)$ & 0.45 & & \\
\hline \multicolumn{5}{|l|}{ Stage } \\
\hline Stage I-II & 1 (reference) & & & \\
\hline Stage III-IV & $1.33(0.62-2.88)$ & 0.46 & & \\
\hline CD68-positive cell density ${ }^{a}$ & $1.11(1.04-1.18)$ & 0.0007 & $1.05(0.98-1.13)$ & 0.17 \\
\hline CD163-positive cell density ${ }^{a}$ & $1.17(1.08-1.29)$ & 0.0001 & $1.13(1.02-1.25)$ & 0.021 \\
\hline
\end{tabular}

For instance, M2 macrophages secrete epidermal growth factor or transforming growth factor- $\beta$, which stimulate epithelial-mesenchymal transition [23, 24]. Sugihara et al. showed that M2 macrophages upregulated expression of Bmi1, which may be a stem cell marker, through microRNA-30e* suppression in GAC [25]. Canan et al. found that TAMs receptor (Tyro3, Axl, and Mertk) upregulated PD-L1 expression in a breast cancer cell line, supporting the idea that M2 macrophages might activate PD-L1 expression in tumor cells [26]. Meanwhile, interferon- $\gamma$ (IFN- $\gamma$ ), which is secreted by inflammatory cells and is associated with differentiation of macrophages, was found to facilitate PD-L1 expression in tumor cells [27-29]. Therefore, IFN- $\gamma$ might influence the relationship between M2 macrophage infiltration and PD-L1 expression in tumor cells. However, no previous reports have addressed M2 macrophage stimulation of PD-L1 expression in GAC. The current study demonstrates a novel relationship between M2 macrophages and PD-L1 expression in GAC cells. The mechanism by which TAMs activate PD-L1 expression in tumor cells requires further research, and we are now evaluating this mechanism in our laboratory.

Our findings suggest that adding macrophage-targeting therapy, such as CSF1/CSF1R blockade, to immune checkpoint blockade therapy may be a viable strategy in GAC. In several types of solid tumors, CSF1/CSF1R blockade reduces $\mathrm{M} 2$ macrophage infiltration into tumor tissue and increases the CD8+/CD4+ $\mathrm{T}$ cell ratio [30]. Zhu et al. showed that adding CSF1R inhibition to $\mathrm{T}$ cell checkpoint immunotherapy increased the effectiveness of treatment by remodeling macrophage and other immune cell infiltration mechanisms and functions in pancreatic cancer [31]. Currently, a clinical trial evaluating the combination of CSF1R antagonists and checkpoint blockade is ongoing (NCT02323191). Our findings suggest that CSF1/CSF1R blockade might reduce PD-L1 expression in tumor cells and suppress direct inhibition of cytotoxic $\mathrm{T}$ cell response by the tumor cells. 


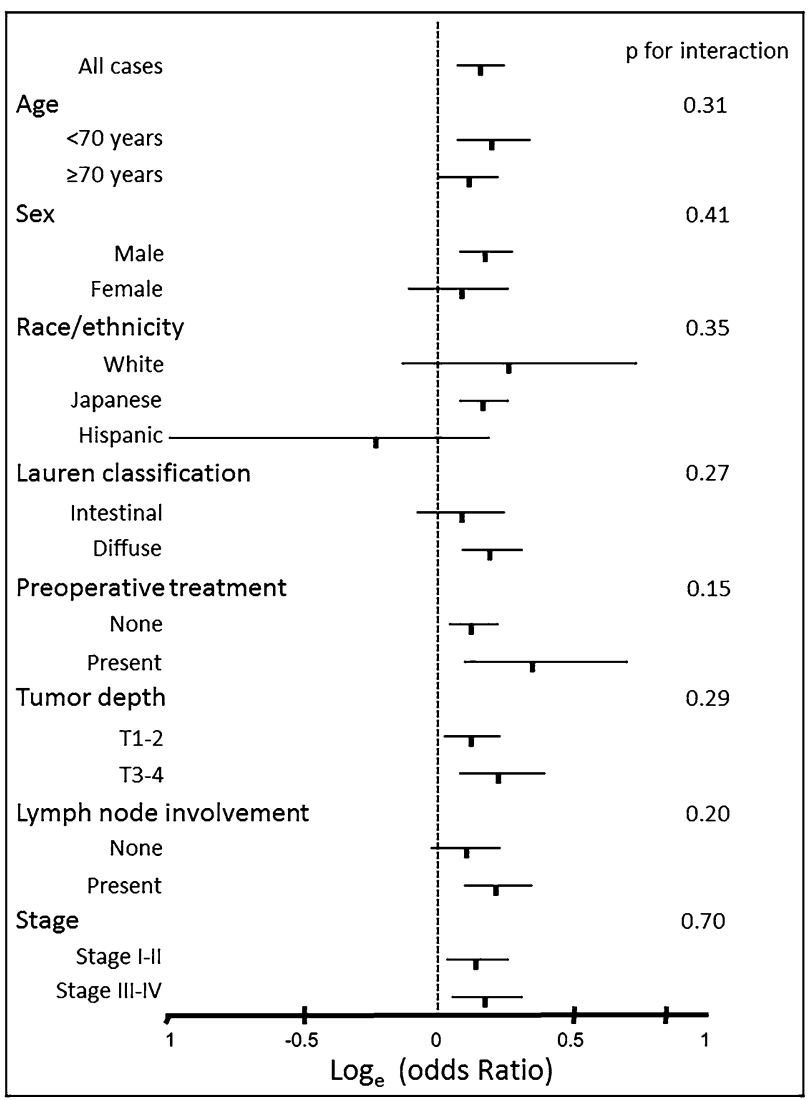

Fig. 3 Interaction between PD-L1 expression in CD163-positive cells in various strata. Shown is the $\log _{\mathrm{e}}$ (odds ratio) plot of PD-L1 expression in the infiltration area of CD163-positive cells for each variable, along with $95 \%$ confidence intervals

Table 4 Univariate analysis of survival

\begin{tabular}{lcc}
\hline Clinical or pathologic feature & Univariate \\
\cline { 2 - 3 } & Hazard ratio (95\% CI) & $p$ value \\
\hline PD-L1 expression (cancer cell) & 1 (reference) & \\
Negative & $0.68(0.31-1.28)$ & 0.25 \\
Positive & 1 (reference) & \\
PD-L1 expression (stroma) & $0.78(0.35-1.53)$ & 0.50 \\
Negative & 1 (reference) & \\
Positive & $0.65(0.36-1.11)$ & 0.13 \\
PD-L1 expression (cancer cell or stroma) & 0.25 \\
Negative & $0.97(0.93-1.02)$ & 0.84 \\
Positive & $0.99(0.94-1.05)$ & \\
CD68-positive cell density & \\
CD163-positive cell density & &
\end{tabular}

CI confidence interval

${ }^{\text {a }}$ Continuous variable
PD-L1 expression was marginally more frequent in Japanese than in Whites or Hispanics. In addition, CD68 infiltration is also marginally higher in Japanese. Lin et al. assessed gene signature differences between Asian and non-Asian GACs and showed that inflammation- and immunity-related $\mathrm{T}$ cell pathways were enriched in nonAsian GACs [32]. Although the molecular biology might differ between Asian and non-Asian GACs, importantly, the contribution of CD163 infiltration to PD-L1 expression was not modified by ethnicity $(p$ for interactions $=0.35$; Fig. 3).

No relationship between PD-L1 and prognosis was found in the current study. This results consistent with a previous study [17]. Some reports showed that PD-L1 expression correlated with favorable prognosis $[19,33]$; on the other hand, some reports showed the opposite results $[18,34]$. Recently, a meta-analysis indicated that PD-L1 expression was associated with an unfavorable prognosis [35]. Further studies are needed to confirm the prognostic value of PD-L1.

PD-L1 expression has intratumoral heterogeneity. This is well evaluated in lung cancer [36-38]. A study in GAC showed intratumoral heterogeneity of PD-L1 expression [19]. Boger et al. reported that 33\% PD-L1-positive GACs have PD-L1 expression cells only in the invasion frontal area or tumor center [19]. In the current study, PD-L1 expression was evaluated in the one point lesion where TMA was made. Thus, multi-point evaluation is needed in further studies.

Recently, molecular classifications, especially microsatellite instability status, were found to be associated with PD-L1 expression [39, 40]. In the current study, the relationship between M2 macrophage infiltration and PD-L1 expression in GAC cells was not influenced by any clinicopathologic variables. However, we did not examine the genetic subtypes of GAC according to The Cancer Genome Atlas.

In conclusion, we found that TAM infiltration is associated with the upregulation of PD-L1 expression in GAC cells. This suggests that macrophage infiltration can serve as a potential therapeutic target.

Acknowledgements This research was supported by generous Grants from the Caporella, Dallas, Sultan, Park, Smith, Frazier, Oaks, Vanstekelenberg, Planjery, and Cantu families as well as from the Schecter Private Foundation, Rivercreek Foundation, Kevin Fund, Myer Fund, Dio Fund, Milrod Fund, and The University of Texas MD Anderson Cancer Center (Houston, TX, USA) multidisciplinary grant program. This research was also supported in part by the National Cancer Institute and Department of Defense awards CA138671, CA172741, CA129926, CA150334 (J.A.A.), and CA160433 (Song S) and by a grant from the Program for Advancing Strategic International Networks to Accelerate the Circulation of Talented Researchers from Japan Society for the Promotion of Science (K.H). 


\section{Compliance with ethical standards}

Conflict of interest The authors have no potential conflicts of interest to disclose.

Human rights statement and informed consent All procedures followed were in accordance with the ethical standards of the responsible committee on human experimentation and with the Helsinki Declaration of 1964 and later versions. Informed consent or a substitute for it was obtained from all patients included in the study.

\section{References}

1. Ferlay J, Soerjomataram I, Dikshit R, Eser S, Mathers C, Rebelo $\mathrm{M}$, et al. Cancer incidence and mortality worldwide: sources, methods and major patterns in GLOBOCAN 2012. Int J Cancer. 2015;136:E359-86.

2. Van Cutsem E, Moiseyenko VM, Tjulandin S, Majlis A, Constenla $\mathrm{M}$, Boni C, et al. Phase III study of docetaxel and cisplatin plus fluorouracil compared with cisplatin and fluorouracil as first-line therapy for advanced gastric cancer: a report of the V325 Study Group. J Clin Oncol. 2006;24:4991-7.

3. Hamid O, Robert C, Daud A, Hodi FS, Hwu WJ, Kefford R, et al. Safety and tumor responses with lambrolizumab (anti-PD-1) in melanoma. N Engl J Med. 2013;369:134-44.

4. Topalian SL, Sznol M, McDermott DF, Kluger HM, Carvajal $\mathrm{RD}$, Sharfman WH, et al. Survival, durable tumor remission, and long-term safety in patients with advanced melanoma receiving nivolumab. J Clin Oncol. 2014;32:1020-30.

5. Le DT, Uram JN, Wang H, Bartlett BR, Kemberling H, Eyring $\mathrm{AD}$, et al. PD-1 blockade in tumors with mismatch-repair deficiency. N Engl J Med. 2015;372:2509-20.

6. Muro K, Chung HC, Shankaran V, Geva R, Catenacci D, Gupta S, et al. Pembrolizumab for patients with PD-L1-positive advanced gastric cancer (KEYNOTE-012): a multicentre, open-label, phase $1 b$ trial. Lancet Oncol. 2016;17:717-26.

7. Chung HC, Arkenau HT, Wyrwicz L, Oh DY, Lee KW, Infante JR, et al. Avelumab (MSB0010718C; anti-PD-L1) in patients with advanced gastric or gastroesophageal junction cancer from JAVELIN solid tumor phase Ib trial: analysis of safety and clinical activity. J Clin Oncol. 2016;15(suppl 1):4009.

8. Chung HC, Arkenau HT, Wyrwicz L, Oh DY, Lee KW, Infante JR, et al. Safety, PD-L1 expression, and clinical activity of avelumab (MSB0010718C), an anti-PD-L1 antibody, in patients with advanced gastric or gastroesophageal junction cancer. J Clin Oncol. 2016;34(suppl 4):167.

9. Brahmer J, Reckamp KL, Baas P, Crino L, Eberhardt WE, Poddubskaya E, et al. Nivolumab versus docetaxel in advanced squamouscell non-small-cell lung cancer. N Engl J Med. 2015;373:123-35.

10. Borghaei H, Paz-Ares L, Horn L, Spigel DR, Steins M, Ready $\mathrm{NE}$, et al. Nivolumab versus docetaxel in advanced nonsquamous non-small-cell lung cancer. N Engl J Med. 2015;373:1627-39.

11. Francisco LM, Sage PT, Sharpe AH. The PD-1 pathway in tolerance and autoimmunity. Immunol Rev. 2010;236:219-42.

12. Noy R, Pollard JW. Tumor-associated macrophages: from mechanisms to therapy. Immunity. 2014;41:49-61.

13. Sica A, Schioppa T, Mantovani A, Allavena P. Tumour-associated macrophages are a distinct M2 polarised population promoting tumour progression: potential targets of anti-cancer therapy. Eur J Cancer. 2006;42:717-27.

14. Ruffell B, Coussens LM. Macrophages and therapeutic resistance in cancer. Cancer Cell. 2015;27:462-72.
15. Greene FLPA, Fleming ID. AJCC cancer staging manual. 6th ed. New York: Springer; 2002. p. 99-106.

16. Kim JW, Nam KH, Ahn SH, Park do J, Kim HH, Kim SH, et al. Prognostic implications of immunosuppressive protein expression in tumors as well as immune cell infiltration within the tumor microenvironment in gastric cancer. Gastric Cancer. 2016;19:42-52.

17. Eto S, Yoshikawa K, Nishi M, Higashijima J, Tokunaga T, Nakao T, et al. Programmed cell death protein 1 expression is an independent prognostic factor in gastric cancer after curative resection. Gastric Cancer. 2016;19:466-71.

18. Tamura T, Ohira M, Tanaka H, Muguruma K, Toyokawa T, Kubo N, et al. Programmed death-1 ligand-1 (PDL1) expression Is associated with the prognosis of patients with stage II/ III gastric cancer. Anticancer Res. 2015;35:5369-76.

19. Boger C, Behrens HM, Mathiak M, Kruger S, Kalthoff H, Rocken C. PD-L1 is an independent prognostic predictor in gastric cancer of Western patients. Oncotarget. 2016;7:24269-83.

20. Zhang L, Qiu M, Jin Y, Ji J, Li B, Wang X, et al. Programmed cell death ligand 1 (PD-L1) expression on gastric cancer and its relationship with clinicopathologic factors. Int J Clin Exp Pathol. 2015;8:11084-91.

21. Herbst RS, Soria JC, Kowanetz M, Fine GD, Hamid O, Gordon MS, et al. Predictive correlates of response to the antiPD-L1 antibody MPDL3280A in cancer patients. Nature. 2014;515:563-7.

22. Qian BZ, Pollard JW. Macrophage diversity enhances tumor progression and metastasis. Cell. 2010;141:39-51.

23. Wyckoff JB, Wang Y, Lin EY, Li JF, Goswami S, Stanley ER, et al. Direct visualization of macrophage-assisted tumor cell intravasation in mammary tumors. Cancer Res. 2007;67:2649-56.

24. Bonde AK, Tischler V, Kumar S, Soltermann A, Schwendener RA. Intratumoral macrophages contribute to epithelial-mesenchymal transition in solid tumors. BMC Cancer. 2012;12:35.

25. Sugihara $H$, Ishimoto $T$, Watanabe $M$, Sawayama $H$, Iwatsuki $\mathrm{M}, \mathrm{Baba} \mathrm{Y}$, et al. Identification of miR-30e* regulation of Bmi1 expression mediated by tumor-associated macrophages in gastrointestinal cancer. PLoS One. 2013;8:e81839.

26. Kasikara C, Kumar S, Kimani S, Tsou WI, Geng K, Davra V, et al. Phosphatidylserine sensing by TAM receptors regulates AKTdependent chemoresistance and PD-L1 expression. Mol Cancer Res. 2017;15:753-64.

27. Abiko K, Matsumura N, Hamanishi J, Horikawa N, Murakami $\mathrm{R}$, Yamaguchi $\mathrm{K}$, et al. IFN-gamma from lymphocytes induces PD-L1 expression and promotes progression of ovarian cancer. Br J Cancer. 2015;112:1501-9.

28. Soliman H, Khalil F, Antonia S. PD-L1 expression is increased in a subset of basal type breast cancer cells. PLoS One. 2014;9:e88557.

29. Chen J, Feng Y, Lu L, Wang H, Dai L, Li Y, Zhang P. Interferon-gamma-induced PD-L1 surface expression on human oral squamous carcinoma via PKD2 signal pathway. Immunobiology. 2012;217:385-93.

30. Ries CH, Cannarile MA, Hoves S, Benz J, Wartha K, Runza V, et al. Targeting tumor-associated macrophages with anti-CSF$1 \mathrm{R}$ antibody reveals a strategy for cancer therapy. Cancer Cell. 2014;25:846-59.

31. Zhu Y, Knolhoff BL, Meyer MA, Nywening TM, West BL, Luo J, et al. CSF1/CSF1R blockade reprograms tumor-infiltrating macrophages and improves response to T-cell checkpoint immunotherapy in pancreatic cancer models. Cancer Res. 2014;74:5057-69.

32. Lin SJ, Gagnon-Bartsch JA, Tan IB, Earle S, Ruff L, Pettinger K, et al. Signatures of tumour immunity distinguish Asian and nonAsian gastric adenocarcinomas. Gut. 2015;64(11):1721-31.

33. Kim JW, Nam KH, Ahn SH, Park DJ, Kim HH, Kim SH, et al. Prognostic implications of immunosuppressive protein 
expression in tumors as well as immune cell infiltration within the tumor microenvironment in gastric cancer. Gastric Cancer. 2016;19(1):42-52.

34. Hou J, Yu Z, Xiang R, Li C, Wang L, Chen S, et al. Correlation between infiltration of FOXP3+ regulatory $\mathrm{T}$ cells and expression of B7-H1 in the tumor tissues of gastric cancer. Exp Mol Pathol. 2014;96(3):284-91.

35. Zhang M, Dong Y, Liu H, Wang Y, Zhao S, Xuan Q, et al. The clinicopathological and prognostic significance of PD-L1 expression in gastric cancer: a meta-analysis of 10 studies with 1901 patients. Sci Rep. 2016;6:37933.

36. McLaughlin J, Han G, Schalper KA, Carvajal-Hausdorf D, Pelekanou V, Rehman J, et al. Quantitative assessment of the heterogeneity of PD-L1 expression in non-small-cell lung cancer. JAMA Oncol. 2016;2(1):46-54.
37. Mansfield AS, Dong H. Implications of programmed cell death 1 ligand 1 heterogeneity in the selection of patients with non-small cell lung cancer to receive immunotherapy. Clin Pharmacol Ther. 2016;100(3):220-2.

38. Kim S, Kim MY, Koh J, Go H, Lee DS, Jeon YK, et al. Programmed death-1 ligand 1 and 2 are highly expressed in pleomorphic carcinomas of the lung: comparison of sarcomatous and carcinomatous areas. Eur J Cancer. 2015;51(17):2698-707.

39. Cancer Genome Atlas Research N. Comprehensive molecular characterization of gastric adenocarcinoma. Nature. 2014;513:202-9.

40. Cristescu R, Lee J, Nebozhyn M, Kim KM, Ting JC, Wong SS, et al. Molecular analysis of gastric cancer identifies subtypes associated with distinct clinical outcomes. Nat Med. 2015;21:449-56. 